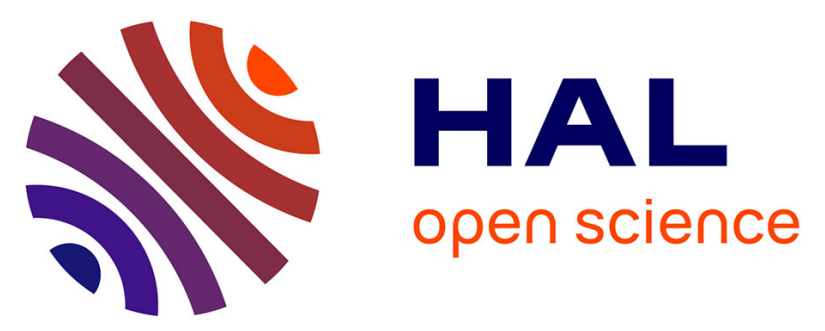

\title{
Outcomes of severe systemic rheumatic disease patients requiring extracorporeal membrane oxygenation
}

Pierre Bay, Guillaume Lebreton, Alexis Mathian, Pierre Demondion, Cyrielle

Desnos, Juliette Chommeloux, Guillaume Hekimian, Nicolas Bréchot, Ania

Nieszkowska, Matthieu Schmidt, et al.

\section{To cite this version:}

Pierre Bay, Guillaume Lebreton, Alexis Mathian, Pierre Demondion, Cyrielle Desnos, et al.. Outcomes of severe systemic rheumatic disease patients requiring extracorporeal membrane oxygenation. Annals of Intensive Care, 2021, 11 (1), 10.1186/s13613-021-00819-3 . hal-03138518

\section{HAL Id: hal-03138518 \\ https://hal.sorbonne-universite.fr/hal-03138518}

Submitted on 11 Feb 2021

HAL is a multi-disciplinary open access archive for the deposit and dissemination of scientific research documents, whether they are published or not. The documents may come from teaching and research institutions in France or abroad, or from public or private research centers.
L'archive ouverte pluridisciplinaire HAL, est destinée au dépôt et à la diffusion de documents scientifiques de niveau recherche, publiés ou non, émanant des établissements d'enseignement et de recherche français ou étrangers, des laboratoires publics ou privés. 


\title{
Outcomes of severe systemic rheumatic disease patients requiring extracorporeal membrane oxygenation
}

Pierre Bay', Guillaume Lebreton², Alexis Mathian ${ }^{3,4}$, Pierre Demondion², Cyrielle Desnos ${ }^{1}$, Juliette Chommeloux', Guillaume Hékimian' ${ }^{1}$, Nicolas Bréchot ${ }^{1}$, Ania Nieszkowska', Matthieu Schmidt ${ }^{1,5}$, Fleur Cohen-Aubart ${ }^{3,4}$, Pascal Leprince ${ }^{2}$, Charles-Edouard Luyt ${ }^{1,5}$, Zahir Amoura ${ }^{3,4}$, Alain Combes ${ }^{1,5}$ and Marc Pineton de Chambrun $1,3,4,5^{*}$

\begin{abstract}
Background: Systemic rheumatic diseases (SRDs) are a group of inflammatory disorders that can require intensive care unit (ICU) admission because of multiorgan involvement with end-organ failure(s). Critically ill SRD patients requiring extracorporeal membrane oxygenation $(E C M O)$ were studied to gain insight into their characteristics and outcomes.

Methods: This French monocenter, retrospective study included all SRD patients requiring venovenous (VV)- or venoarterial (VA)-ECMO admitted to a 26-bed ECMO-dedicated ICU from January 2006 to February 2020. The primary endpoint was in-hospital mortality.

Results: Ninety patients (male/female ratio: 0.5; mean age at admission: $41.6 \pm 15.2$ years) admitted to the ICU received VANV-ECMO, respectively, for an SRD-related flare $(n=69, n=38 / 31)$ or infection $(n=21, n=10 / 11)$. SRD was diagnosed in-ICU for 31 (34.4\%) patients. In-ICU and in-hospital mortality rates were 48.9 and $51.1 \%$, respectively. Nine patients were bridged to cardiac $(n=5)$ or lung transplantation $(n=4)$, or left ventricular assist device $(n=2)$. The Cox multivariable model retained the following independent predictors of in-hospital mortality: in-ICU SRD diagnosis, day-0 Simplified Acute Physiology Score (SAPS) II score $\geq 70$ and arterial lactate $\geq 7.5 \mathrm{mmol} / \mathrm{L}$ for VA-ECMO-treated patients; diagnosis other than vasculitis, day-0 SAPS II score $\geq 70$, ventilator-associated pneumonia and arterial lactate $\geq 7.5 \mathrm{mmol} / \mathrm{L}$ for $\mathrm{V}$-ECMO-treated patients.
\end{abstract}

Conclusions: ECMO support is a relevant rescue technique for critically ill SRD patients, with 49\% survival at hospital discharge. Vasculitis was independently associated with favorable outcomes of $\mathrm{V}$-ECMO-treated patients. Further studies are needed to specify the role of ECMO for SRD patients.

Keywords: Systemic rheumatic disease, Extracorporeal membrane oxygenation, Intensive care unit, Vasculitis, Systemic lupus erythematosus, Connective tissue disease, Acute respiratory distress syndrome, Cardiogenic shock

*Correspondence: marc.dechambrun@gmail.com

1 Service de Médecine Intensive-Réanimation, Hôpital La Pitié-Salpêtrière, Sorbonne Université, Assistance Publique-Hôpitaux de Paris (APHP), Paris, France

Full list of author information is available at the end of the article

\section{Introduction}

Systemic rheumatic diseases (SRDs) are a group of inflammatory disorders (including connective tissue diseases, rheumatic disorders, vasculitides, sarcoidosis, adult-onset Still's disease...) involving more than one organ and often requiring immunosuppressant therapy [1]. They share common characteristics: multiorgan 
involvement responsible for end-organ failures; specific treatments causing immunosuppression and infectious complications; and are rare entities with challenging diagnoses and diagnostic difficulties. Outcomes of SRD patients requiring ICU admission remain unclear, with $16 \%-33 \%$ reported in-ICU mortality [1-4].

Extracorporeal membrane oxygenation (ECMO) is a rescue technique used to temporarily replace the heart and/or lung functions of the most severe patients $[5,6]$. It may serve as a bridge-to-recovery or a bridge-to-organ transplantation for patients with treatment-refractory heart and/or lung failure(s).

We undertook this study to determine the outcome and identify in-hospital mortality associated factors of critically ill SRD patients receiving ECMO.

\section{Methods}

\section{Patients}

We retrospectively reviewed the prospectively constituted ECMO database of our 26-bed ICU to identify adult SRD patients who received, between January 2006 and February 2020, venoarterial (VA)-ECMO and/ or venovenous (VV)-ECMO for heart and/or lung endorgan failure(s). SRD were identified searching in all medical charts a large number of keywords referring to SRD including: systemic rheumatic disease; connective tissue disease; lupus; systemic sclerosis; scleroderma; antiphospholipid; myositis; inflammatory myopathy; Sharp; Sjögren; Gougerot; rheumatoid arthritis; spondylarthritis; vasculitides; Goodpasture; antineutrophil cytoplasmic antibodies; proteinase 3 ; myeloperoxidase; Henoch-Schönlein; sarcoidosis; Still's disease; eosinophilia; myasthenia; neuromyelitis optica... Our tertiary ICU is an ECMO-referral center for Greater Paris. Patients with the following SRDs were considered for inclusion: connective tissue diseases, vasculitides, sarcoidosis, nonmalignant eosinophilia-related disorders, adult-onset Still's disease and other organ-specific autoimmune diseases with more than one organ involved.

\section{ECMO implantation}

The detailed surgical procedure for femoral-femoral VAECMO or femoral-jugular VV-ECMO placement was described previously [7-9]. Briefly, trained cardiovascular surgeons performed all procedures in-ICU at bedside or in the cardiac angiography room because of patient's hemodynamic instability. Femoral and/or jugular vessels were cannulated after limited cut-down using the Seldinger technique and, for VA-ECMO, an additional 7 French catheter was systematically inserted distally into the femoral artery to prevent severe leg ischemia. For highly unstable patients diagnosed with refractory cardiogenic shock or acute respiratory distress syndrome
(ARDS) in other hospitals, our institution's Mobile ECMO Retrieval Team traveled rapidly to primary-care hospitals with a portable ECMO system, installed the device before refractory multiorgan failure or ARDS occurred, and then transported the patient to our tertiary-care center [10].

\section{Study endpoints}

The primary endpoint was in-hospital mortality, defined as death during the hospital stay consecutive to the first ICU admission and before the patient's discharge to home. The secondary outcomes included ECMO weaning: bridge-to-recovery, bridge-to-transplantation (lung or cardiac) and bridge-to-long term ventricle assist device.

\section{Data collection}

The following information was collected on standardized forms: epidemiological parameters; SRD clinical, biological and therapeutic history; clinical manifestations; laboratory findings; ECMO type, indication and complication(s); Survival after Veno-Arterial ECMO (SAVE) [11] and Respiratory Extracorporeal Membrane Oxygenation Survival Prediction (RESP) [12] scores, that are survival predictors in VA-ECMO and VV-ECMO patients, respectively; in-ICU treatments; organ-support treatments; SRD-specific treatments introduced in the ICU; ECMO-weaning status; bridge-to-transplantation or left ventricular assist device (LVAD); ICU complications; vital status, transplantation status at ICU and hospital discharges and at last follow-up.

\section{Statistical analyses}

Results for categorical variables, expressed as number (\%), were compared with $\chi^{2}$ tests; those for continuous variables, expressed as mean \pm standard deviation or median [25-75th percentile interquartile range (IQR)], were compared using Student's $t$-test or Wilcoxon's rank test. Normality of continuous variable distribution was assessed with the Shapiro-Wilk test; when not normal, Wilcoxon's rank test was used for comparisons.

First, patients' characteristics (laboratory findings, in-ICU organ-failure treatment(s), SRD-specific manifestations and treatment(s), complications and outcomes) were subjected to descriptive analysis. Next, the mean/median values and frequencies of patients' characteristics were compared according to the primary endpoint for the entire population and in the following subgroups: flare-related admission and VA/VV-ECMO. Then, for each subgroup, a Cox proportional hazards model, including the variables associated with the primary endpoint (entry threshold: $P<0.05$ ), was run using backward-stepwise variable elimination (exit threshold: 
$P>0.10)$. Continuous variable were dichotomized to using the cut-offs with the best association with the primary endpoint in univariable Cox proportional hazards model. All potential explanatory variables included in the multivariable analyses were subjected to colinearity analysis with a correlation matrix. When colinearity was found (variance inflation factor $>5$ ), only one of the two variables could be included the model. Statistical significance was defined as $P<0.05$. Analyses were computed with IBM SPSS Statistics v22.0 software (IBM Corp, Armonk, NY).

\section{Ethical considerations}

The database is registered with the "Commission Nationale de l'Informatique et des Libertés" $(2217847 \mathrm{v} 0)$. In accordance with the ethical standards of our hospital's institutional review board, the Committee for the Protection of Human Subjects, and French law, written informed consent was not needed for demographic, physiological and hospital-outcome data analyses, because this observational study did not modify existing diagnostic or therapeutic strategies; however, patients were informed of their inclusion in the study.

\section{Results}

\section{General characteristics}

During the study period, 90 SRD patients requiring ICU admission (male/female ratio: 0.5; mean age at ICU admission: $41.6 \pm 15.2$ years) received VV-ECMO $(n=42$, $46.7 \%)$ or VA-ECMO $(n=48,53.3 \%)$. Their demographics and the SRD characteristics are detailed in Table 1 and Additional file 1: Table S1. SRD was diagnosed in-ICU for $34.4 \%$ patients. The main diagnoses were: connective tissue disease $(57.8 \%)$, vasculitis $(11.1 \%)$, rheumatic disorders $(11.1 \%)$ and sarcoidosis $(5.6 \%)$. The organs most frequently affected pre-admission were: lung (47.8\%), joints (38.9\%), skin, heart and kidney. Before ICU admission, $47.8 \%$ of the patients took corticosteroids regularly and $36.7 \%$ immunosuppressants. Three-quarters were admitted for an SRD flare and about one-quarter for an infection. The flow chart reports patients' outcomes according to the reason for admission and ECMO hookup (Fig. 1). In-ICU mortality, in-hospital mortality and in-hospital mortality/LVAD/ transplantation rates were: 48.9, 51.1 and $60.0 \%$.

The main ECMO complications were cannula-related infection, insertion-site hemorrhage and limb ischemia. In-ICU-acquired infections occurred in $65.6 \%$ of patients; their sites and pathogens are reported in Additional file 1: Table S2.
Table 1 Characteristics of 90 SRD patients given ECMO support

\begin{tabular}{|c|c|}
\hline Variables & Value \\
\hline Women & $60(66.7)$ \\
\hline Body mass index, $\mathrm{kg} / \mathrm{m}^{2}$ & $26.3 \pm 6.8$ \\
\hline Age at ICU admission, years & $41.6 \pm 15.2$ \\
\hline \multicolumn{2}{|l|}{ Systemic rheumatic diseases } \\
\hline Diagnosis in the ICU & $31(34.4)$ \\
\hline Diagnosis-to-ICU interval*, months & $93(25-132)$ \\
\hline Connective tissue diseases & $52(57.8)$ \\
\hline Systemic lupus erythematosus & $22(24.4)$ \\
\hline Idiopathic inflammatory myositis & $12(13.3)$ \\
\hline Antiphospholipid syndrome & $12(13.3)$ \\
\hline Systemic sclerosis & $5(5.6)$ \\
\hline Mixed connective tissue disease & $5(5.6)$ \\
\hline Sjögren's syndrome & $3(3.3)$ \\
\hline Rheumatic disorders & $10(11.1)$ \\
\hline Vasculitides & $10(11.1)$ \\
\hline Goodpasture's syndrome & $3(3.3)$ \\
\hline ANCA-associated & $5(5.6)$ \\
\hline Small-vessel & $1(1.1)$ \\
\hline IgA-associated & $1(1.1)$ \\
\hline Sarcoidosis & $5(5.6)$ \\
\hline Nonmalignant eosinophilia-related diseases & $4(4.4)$ \\
\hline Adult-onset Still's disease & $4(4.4)$ \\
\hline Others $^{\dagger}$ & $5(5.6)$ \\
\hline \multicolumn{2}{|l|}{ Pre-ICU Specific treatment(s) } \\
\hline Corticosteroids & $43(47.8)$ \\
\hline Immunosuppressant(s) ${ }^{\S}$ & $33(36.7)$ \\
\hline Flare-related admission & $69(76.7)$ \\
\hline Infection-related admission & $21(23.3)$ \\
\hline
\end{tabular}

Continuous variables are expressed as mean \pm standard deviation or median [interquartile range]; categorical variables are expressed as $n$ (\%)

ICU intensive care unit, ANCA antineutrophil cytoplasm antibodies, ECMO extracorporeal membrane oxygenation, $S R D$ systemic rheumatic disease

* Three missing data

† One each: myasthenia gravis, neuromyelitis optica, multicentric Castleman's disease, autoimmune thrombocytopenic purpura or inflammatory bowel disease

$\S$ Methotrexate $n=15$, azathioprine $n=13$, mycophenolate mofetil $n=9$, cyclophosphamide $n=8$, rituximab $n=6$, tumor necrosis factor-inhibitor $n=6$, calcineurin inhibitors $n=5$, tocilizumab $n=2$

\section{Uni- and multivariable analyses of in-hospital mortality-associated factors}

Nonsurvivors, compared to survivors, were less quickly admitted to the ICU after symptom onset and hospital admission, had more frequent SRD heart involvement before admission, higher day-0 SAPS II and SOFA scores, lower RESP and SAVE scores, and more frequently received vasopressors and renal replacement therapy in ICU (Table 2). Nonsurvivors also had more frequent inICU-acquired infections, especially fungal, and ECMO 


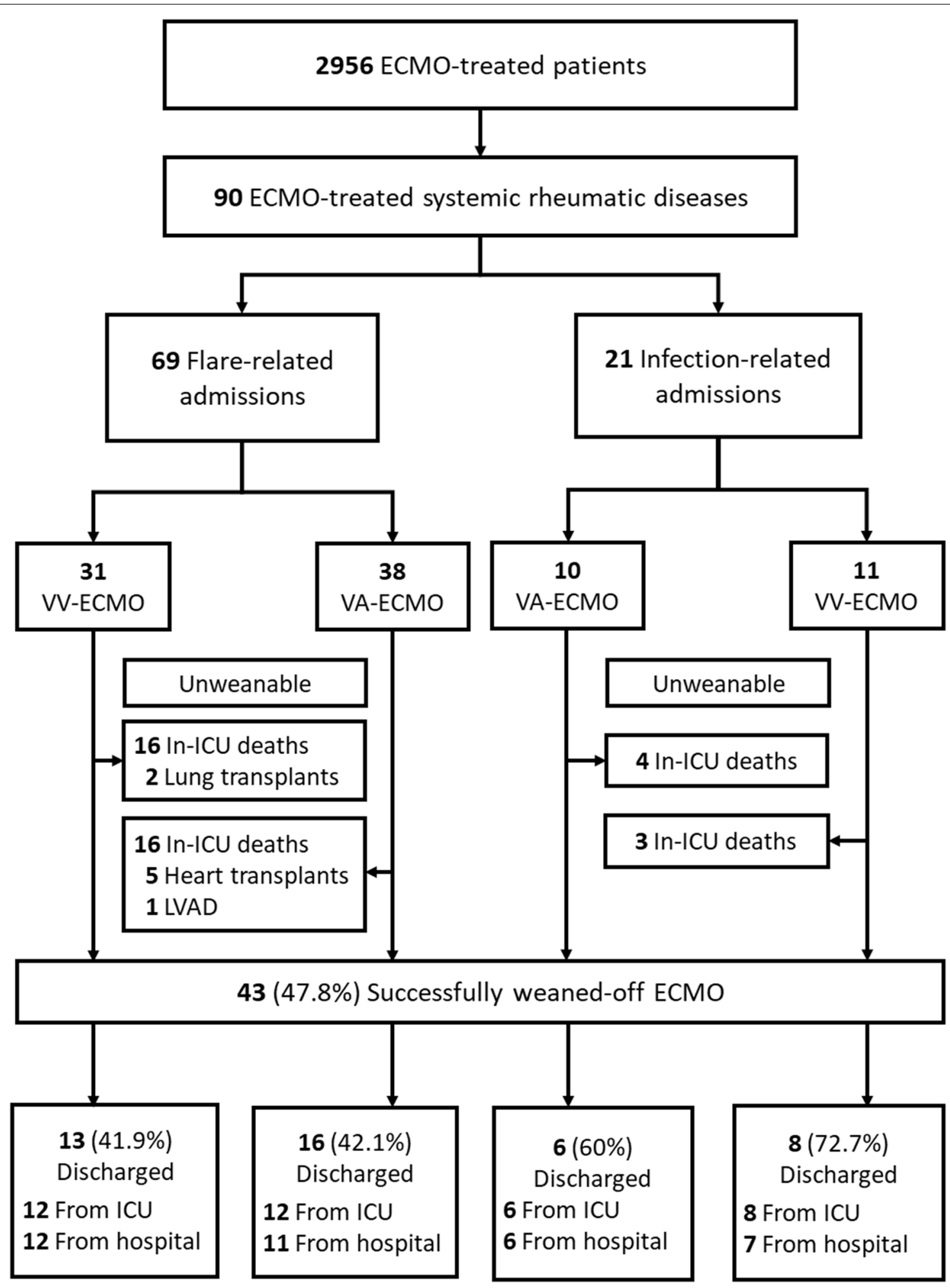

Fig. 1 Flow chart of the 90 patients with systemic rheumatic disease requiring extracorporeal membrane oxygenation. ICU intensive care unit, LVAD left ventricular assist device, VAW-ECMO venoarterial/venovenous-extracorporeal membrane oxygenation 
Table 2 In-ICU characteristics and outcomes of the 90 ECMO-treated SRD patients: hospital survivors vs. nonsurvivors

\begin{tabular}{|c|c|c|c|c|}
\hline Characteristic & $n / n^{*}$ & $\begin{array}{l}\text { Survivors } \\
n=44\end{array}$ & $\begin{array}{l}\text { Nonsurvivors } \\
n=46\end{array}$ & $P$ value \\
\hline Women & & $26(59.1)$ & $34(73.9)$ & 0.1 \\
\hline Age at admission, years & & $38.9 \pm 15.6$ & $44.2 \pm 14.5$ & 0.1 \\
\hline Symptom-onset-to-ICU interval, days & & $8[3-21.5]$ & $16[6-41]$ & 0.03 \\
\hline Hospital-to-ICU interval, days & & $3.5[1-8]$ & 8 [3-19] & 0.007 \\
\hline Days in ICU & & 19 [9-59] & $17[5-37]$ & 0.1 \\
\hline \multicolumn{5}{|l|}{ Pre-ICU-admission SRD } \\
\hline Connective tissue diseases & & $23(52.3)$ & $29(63.0)$ & 0.3 \\
\hline Vasculitides & & $7(15.9)$ & $3(6.5)$ & 0.2 \\
\hline Corticosteroids & & $17(38.6)$ & $26(56.5)$ & 0.1 \\
\hline Immunosuppressant(s) & & $14(31.8)$ & $19(41.3)$ & 0.4 \\
\hline Heart involvement & & $7(15.9)$ & $16(34.8)$ & 0.04 \\
\hline \multicolumn{5}{|l|}{ In-ICU SRD } \\
\hline Flare-related admission & & $31(70.5)$ & $38(82.6)$ & 0.2 \\
\hline In-ICU diagnosis & & $14(31.8)$ & $17(37)$ & 0.6 \\
\hline Corticosteroids & & $28(63.6)$ & $30(65.2)$ & 0.9 \\
\hline Immunosuppressant(s) & & $13(29.5)$ & $18(39.1)$ & 0.3 \\
\hline \multicolumn{5}{|l|}{ Organ failure at ICU admission } \\
\hline Day-0 SAPS II & & $57[45-66]$ & $62[48-75]$ & 0.07 \\
\hline Day-0 SOFA score & & $12[9-15]$ & 15 [12-18] & 0.01 \\
\hline \multicolumn{5}{|l|}{ ECMO } \\
\hline V-ECMO & & $21(47.7)$ & $21(45.7)$ & 0.8 \\
\hline RESP score & & $2[-0.5$ to 3$]$ & $-2[-4$ to 0$]$ & 0.001 \\
\hline VA-ECMO & & $23(52.3)$ & $25(54.3)$ & 0.8 \\
\hline SAVE score & & $-0.5[-6$ to 1.7$]$ & $-11[-15$ to -5$]$ & 0.001 \\
\hline Days on ECMO & & $8[5-22.2]$ & $8[1-20.2]$ & 0.2 \\
\hline \multicolumn{5}{|l|}{ ECMO complication } \\
\hline Limb ischemia & & $6(13.6)$ & $5(10.9)$ & 0.7 \\
\hline Insertion-site hemorrhage & & $6(13.6)$ & $14(30.4)$ & 0.06 \\
\hline Cannula-related infection & & $10(22.7)$ & $10(21.7)$ & 0.9 \\
\hline \multicolumn{5}{|l|}{ In-ICU organ support } \\
\hline Dobutamine & & $23(52.3)$ & $20(43.5)$ & 0.4 \\
\hline Vasopressors & & $38(86.4)$ & $45(97.8)$ & 0.04 \\
\hline Mechanical ventilation & & $42(95.5)$ & $45(97.8)$ & 0.5 \\
\hline Renal replacement therapy & & $18(40.9)$ & $31(67.4)$ & 0.01 \\
\hline \multicolumn{5}{|l|}{ Highest in-ICU value } \\
\hline Arterial lactate, $\mathrm{mmol} / \mathrm{L}$ & $43 / 46$ & $6.4[3.2-10]$ & 13 [5.9-18] & 0.001 \\
\hline Troponin, ULN & $39 / 45$ & $13.2[4.4-41.7]$ & $10.7[1.8-53.2]$ & 0.5 \\
\hline Serum creatinine, $\mu \mathrm{mol} / \mathrm{L}$ & $42 / 41$ & $143[89-342]$ & $147[93-218]$ & 0.8 \\
\hline \multicolumn{5}{|l|}{ Lowest in-ICU value } \\
\hline Platelet count, G/L & $43 / 46$ & $56[30-103]$ & $23[7-40]$ & $<0.0001$ \\
\hline Prothrombin time, $\%$ & $43 / 46$ & $47[37-60]$ & $34[16-55]$ & 0.005 \\
\hline \multicolumn{5}{|l|}{ Outcome } \\
\hline In-ICU-acquired infection & & $26(59.1)$ & $33(71.7)$ & 0.2 \\
\hline Fungal infection & & $3(6.8)$ & $11(23.9)$ & 0.02 \\
\hline Transplantation & & $8(18.2)$ & $1(2.2)$ & 0.01 \\
\hline Heart & & $3(6.8)$ & $1(2.2)$ & $\mathrm{n} / \mathrm{a}$ \\
\hline Heart-kidney combined & & $1(2.3)$ & $0(0)$ & $\mathrm{n} / \mathrm{a}$ \\
\hline Lung & & $4(9.1)$ & $0(0)$ & $\mathrm{n} / \mathrm{a}$ \\
\hline Left ventricular assist device & & $1(2.3)$ & $1(2.2)$ & 0.9 \\
\hline
\end{tabular}


Table 2 (continued)

\begin{tabular}{|c|c|c|c|c|}
\hline Characteristic & $n / n^{*}$ & $\begin{array}{l}\text { Survivors } \\
n=44\end{array}$ & $\begin{array}{l}\text { Nonsurvivors } \\
n=46\end{array}$ & $P$ value \\
\hline Weaning & & $36(81.8)$ & $7(15.2)$ & $<0.0001$ \\
\hline In-ICU mortality & & $0(0)$ & $44(95.7)$ & $<0.0001$ \\
\hline
\end{tabular}

Continuous variables are expressed as mean \pm standard deviation or median [interquartile range] and compared with Student's $t$-test or Wilcoxon's rank test; categorical variables are expressed as $n(\%)$ and compared with $x^{2}$ tests

ICU intensive care unit, LVEF left ventricle ejection fraction, RESP Respiratory Extracorporeal Membrane Oxygenation Survival Prediction, SAPS Simplified Acute Physiology Score, SAVE Survival after Veno-Arterial ECMO, SOFA Sequential Organ-Failure Assessment, SRD systemic rheumatic disease, VA-/VV-ECMO venoarterial/ venovenous-extracorporeal membrane oxygenation, ULN upper limit of normal value, VTI velocity-time integral

* Numbers of survivor/nonsurvivor data available

insertion-site hemorrhages. The frequencies of flarerelated admissions, in-ICU SRD diagnoses and VA/VVECMO percentages were not different for the two groups.

The Cox proportional hazards model univariable and multivariable analyses for the 90 SRD patients (Table 3) retained: pre-admission SRD heart involvement; day-0 SAPS II score $\geq 70$; arterial lactate $\geq 7.5 \mathrm{mmol} / \mathrm{L}$ and bilirubin $\geq 125 \mu \mathrm{mol} / \mathrm{L}$, as independently associated with in-hospital mortality.

Uni- and multivariable analyses of in-hospital mortality-associated factors: flare-related admissions Among the 69 flare-related admissions: $44.9 \%$ patients received VV-ECMO and 55.1\% VA-ECMO, 21 could be

Table 3 Univariable and multivariable analyses of factors associated with in-hospital mortality for the 90 ECMO-treated SRD patients

\begin{tabular}{|c|c|c|c|c|c|c|}
\hline \multirow[t]{2}{*}{ Factor } & \multicolumn{3}{|c|}{ Univariable analysis } & \multicolumn{3}{|c|}{ multivariable analysis } \\
\hline & HR & $95 \% \mathrm{Cl}$ & $P$ value & HR & $95 \% \mathrm{Cl}$ & $P$ value \\
\hline Age $\geq 40$ years & 1.4 & $0.8-2.5$ & 0.3 & & & \\
\hline Women & 1.5 & $0.8-2.9$ & 0.2 & & & \\
\hline Pre-admission SRD lung involvement & 0.5 & $0.3-0.9$ & 0.04 & 0.8 & $0.4-1.6$ & 0.6 \\
\hline Pre-admission SRD heart involvement & 1.7 & $0.9-3.2$ & 0.08 & 2.9 & $1.5-5.8$ & 0.001 \\
\hline Corticosteroids before admission & 1.7 & $0.9-3.1$ & 0.07 & 1.8 & $0.9-3.3$ & 0.052 \\
\hline Immunosuppressants before admission & 1.3 & $0.7-2.3$ & 0.4 & & & \\
\hline In-ICU SRD diagnosis & 1.0 & $0.6-1.9$ & 0.9 & & & \\
\hline Day-0 SAPS $\| \geq 70$ & 2.7 & $1.5-4.9$ & 0.001 & 2.7 & $1.4-5.1$ & 0.003 \\
\hline Day-0 SOFA score $\geq 16$ & 2.8 & $1.6-5.1$ & $<0.0001$ & & & \\
\hline Flare-related admission & 1.4 & $0.6-3.0$ & 0.7 & & & \\
\hline VA-ECMO & 1.3 & $0.7-2.4$ & 0.3 & & & \\
\hline In-ICU corticosteroids & 0.8 & $0.4-1.5$ & 0.5 & & & \\
\hline In-ICU immunosuppressant(s) & 1.0 & $0.5-1.8$ & 0.9 & & & \\
\hline Vasopressors & 5.3 & $0.7-38.6$ & 0.1 & 2.7 & $0.3-21.0$ & 0.3 \\
\hline Mechanical ventilation & 1.8 & $0.2-13.2$ & 0.5 & & & \\
\hline Renal replacement therapy & 2.2 & $1.2-4.0$ & 0.01 & 0.6 & $0.2-1.4$ & 0.2 \\
\hline ICU-acquired infection & 1.0 & $0.6-2.0$ & 0.9 & & & \\
\hline \multicolumn{7}{|l|}{ Highest in-ICU value } \\
\hline Arterial lactate $\geq 7.5 \mathrm{mmol} / \mathrm{L}$ & 3.2 & $1.7-5.9$ & $<0.0001$ & 2.8 & $1.4-5.3$ & 0.002 \\
\hline Bilirubin $\geq 125 \mu \mathrm{mol} / \mathrm{L}$ & 2.3 & $1.2-4.3$ & 0.007 & 2.0 & $1.0-3.9$ & 0.04 \\
\hline \multicolumn{7}{|l|}{ Lowest in-ICU value } \\
\hline Platelet count <50 G/L & 2.9 & $1.4-6.0$ & 0.004 & 1.8 & $0.7-4.5$ & 0.2 \\
\hline
\end{tabular}

Bold values indicates statistically significant in multivariable analysis

The multiple Cox proportional hazards model used backward-stepwise variable elimination (with variable exit threshold set at $P>0.10$ ). All potential explanatory variables included in the multivariable analyses were subjected to colinearity analysis with a correlation matrix. Variables associated with one another were not included in the model. Statistical significance was defined as $P<0.05$

ICU intensive care unit, SAPS Simplified Acute Physiology Score, SOFA sequential organ failure assessment, SRD systemic rheumatic diseases, VA-ECMO venoarterialextracorporeal membrane oxygenation 
weaned-off ECMO and 10 were bridged-to-transplant $(n=8)$ or -LVAD $(n=2)$. Nonsurvivors, compared to survivors, had more frequent SRD heart involvement before admission, higher day-SOFA scores, lower RESP and SAVE scores, and more frequently received vasopressors and renal replacement therapy in ICU (Table 4).

Similarly to the whole cohort, the Cox proportional hazards model univariable and multivariable analyses (Table 5) retained: pre-admission SRD heart involvement, day-0 SAPS II score $\geq 70$, arterial lactate $\geq 7.5 \mathrm{mmol} / \mathrm{L}$ and bilirubin $\geq 125 \mu \mathrm{mol} / \mathrm{L}$, as independently associated with in-hospital mortality.

\section{Uni- and multivariable analyses of VA-ECMO-associated in-hospital mortality factors}

Among the 48 VA-ECMO patients, 23 (47.9\%) survived to hospital discharge. Nonsurvivors, compared to survivors, more frequently had SRD heart involvement before admission, higher day-0 SAPS II and SOFA scores, lower left ventricular ejection fraction before cannulation and SAVE scores, more frequently received in-ICU vasopressors and renal replacement therapy, and more frequently experienced in-ICU cardiac arrest (Additional file 1: Table S3).

The Cox proportional hazards model univariable and multivariable analyses for the 48 patients given VAECMO support (Additional file 1: Table S4) retained: inICU SRD diagnosis, day-0 SAPS II score $\geq 70$ and arterial lactate $\geq 7.5 \mathrm{mmol} / \mathrm{L}$ as independently associated with in-hospital mortality.

\section{Uni- and multivariable analyses of VV-ECMO-associated in-hospital mortality-associated factors}

Among the 42 patients receiving VV-ECMO, 21 (50.0\%) survived to hospital discharge. Nonsurvivors, compared to survivors, were less quickly admitted to the ICU after symptom onset and hospital admission; had vasculitis less frequently, lower RESP scores and more in-ICUacquired infections, especially ventilator-associated pneumonia and invasive fungal infection (Additional file 1: Table S5).

The Cox proportional hazards model univariable and multivariable analyses for these 42 patients (Additional file 1: Table S6) retained: vasculitis, day-0 SAPS II score $\geq 70$, ICU-acquired ventilator-associated pneumonia and arterial lactate $\geq 7.5 \mathrm{mmol} / \mathrm{L}$, as independently associated with in-hospital mortality.

\section{Discussion}

SRDs are heterogeneous diseases, whose severe organ involvement may lead to end-organ failure requiring ICU admission. Their rarity makes diagnoses sometimes difficult and management of critically ill patients a delicate undertaking. When end-organ lung or heart failure occurs, the capacity to recover is uncertain, especially for chronic SRD involvement, even with the latest therapeutic innovations. ECMO is an emerging rescue therapy, whose indications for VV [13] or VA hook-up [14] have not yet been clearly delineated. Data are urgently awaited to support or refute the indication of ECMO for SRD patients.

Herein, we report the largest series of ECMO-treated, severely ill SRD patients. Available literature is scarce, other than multiple case reports, and ECMO use was anecdotical in previous populations: $6(1.6 \%)$ patients in the study by Dumas and colleagues [2], $6(7.3 \%)$ and 3 (3.1\%) in the largest ICU studies on antineutrophil cytoplasm antibody-associated vasculitides $[15,16]$. A significant number of the $62(11.8 \%)$ ECMO-treated patients in Larcher and colleagues' recent paper [3] were managed in our center and are also included herein, however this study did not specifically addressed the characteristics, management and outcomes of ECMO-treated patients and, therefore, does not duplicate the results of the present study.

Our analyses identified several new findings. Unlike previous studies, most of our patients were admitted for an SRD flare and only a quarter for an infection. This inverse proportion reflects bias related to the population for which ECMO is indicated: a small percentage of bacterial/viral pneumonias require VV-ECMO implantation and few infections (mainly severe septic shock) will need VA-ECMO cannulation. At the same time, the number of patients admitted for their first SRD manifestation was particularly high: one-third of our patients vs. onetenth in previous reports [2,3]. While those admissions for infection had usually been associated with worse outcomes, the in-hospital survival rates of our flare and infection patients were similar. Some classical, ICUprognostic factors were not associated with in-hospital mortality, particularly: age, mechanical ventilation, vasopressor use and renal replacement therapy. That finding probably reflects the stringent selection of our patients and the very high level of in-ICU organ support that most of them received.

Our in-hospital mortality was significantly higher than previously reported. Indeed, the main series of critically ill SRD patients reported $16-21 \%$ in-ICU $[2,4]$ and $20-43 \%$ in-hospital-mortality rates $[1,3,17-21]$. However, our patients were obviously more severely ill, as shown by their higher median day-0 SOFA scores and day-0 SAPS II, respectively: 13.5 vs. 5-7.2 [2, 3, 19] and 59 vs. $29-45[3,4,21]$. Moreover, our in-hospital-mortality rate was similar to those of ESLO patients: $\sim 43 \%$ VV-ECMO-treated [12] and 58\% VA-ECMO-treated [11]. 
Table 4 In-ICU characteristics and outcomes of the 69 ECMO-treated SRD flare patients: hospital survivors vs. nonsurvivors

\begin{tabular}{|c|c|c|c|c|}
\hline Characteristic & $n / n^{*}$ & $\begin{array}{l}\text { Survivors } \\
n=31\end{array}$ & $\begin{array}{l}\text { Nonsurvivors } \\
n=38\end{array}$ & Pvalue \\
\hline Women & & $16(51.6)$ & $27(71.1)$ & 0.1 \\
\hline Age at admission, years & & $37.6 \pm 16.2$ & $44.5 \pm 14.6$ & 0.07 \\
\hline Symptom-onset-to-ICU interval, days & & $8[3-23]$ & $18[7-42]$ & 0.02 \\
\hline Hospital-to-ICU interval, days & & $3[1-8]$ & $9[4-22.2]$ & 0.002 \\
\hline Days in ICU & & 19 [9-77] & $17[5-36]$ & 0.1 \\
\hline \multicolumn{5}{|l|}{ Pre-admission SRD } \\
\hline Connective tissue diseases & & $15(48.4)$ & $34(89.5)$ & 0.2 \\
\hline Vasculitides & & $6(19.4)$ & $3(7.9)$ & 0.2 \\
\hline Corticosteroids & & $10(32.3)$ & $19(50)$ & 0.1 \\
\hline Immunosuppressant(s) & & $7(22.6)$ & $13(34.2)$ & 0.3 \\
\hline Heart involvement & & $6(19.4)$ & $16(42.1)$ & 0.04 \\
\hline \multicolumn{5}{|l|}{ In-ICU SRD } \\
\hline In-ICU diagnosis & & $12(38.7)$ & $17(44.7)$ & 0.6 \\
\hline Corticosteroids & & $24(77.4)$ & $29(76.3)$ & 0.9 \\
\hline Immunosuppressant(s) & & $12(38.7)$ & $18(47.4)$ & 0.5 \\
\hline \multicolumn{5}{|l|}{ Organ failures at ICU admission } \\
\hline Day-0 SAPS II & & $55[30-66]$ & $62[48-73]$ & 0.06 \\
\hline Day-0 SOFA score & & $12[8-14]$ & 15 [12-18] & 0.006 \\
\hline \multicolumn{5}{|l|}{ ECMO } \\
\hline W-ECMO & & $14(45.2)$ & $17(44.7)$ & 0.9 \\
\hline RESP score & & $1.5[-0.2$ to 3$]$ & $-2[-4$ to 0$]$ & 0.007 \\
\hline VA-ECMO & & $17(54.8)$ & $21(55.3)$ & 0.9 \\
\hline SAVE score & & $0[-6$ to 1$]$ & $-8.5[-13.7$ to -3.5$]$ & 0.001 \\
\hline Days on ECMO & & $48[7-73]$ & $11[4-29]$ & 0.2 \\
\hline \multicolumn{5}{|l|}{ ECMO complications } \\
\hline Limb ischemia & & $3(9.7)$ & $3(7.9)$ & 0.8 \\
\hline Insertion-site hemorrhage & & $5(16.1)$ & $10(26.3)$ & 0.1 \\
\hline Cannula-related infection & & $8(25.8)$ & $7(18.4)$ & 0.5 \\
\hline \multicolumn{5}{|l|}{ In-ICU organ support } \\
\hline Dobutamine & & $18(58.1)$ & $16(42.1)$ & 0.2 \\
\hline Vasopressors & & 25 (80.6) & $37(97.4)$ & 0.02 \\
\hline Mechanical ventilation & & $29(93.5)$ & $37(97.4)$ & 0.4 \\
\hline Renal replacement therapy & & $11(35.5)$ & $24(63.2)$ & 0.02 \\
\hline \multicolumn{5}{|l|}{ Highest in-ICU value } \\
\hline Arterial lactate, $\mathrm{mmol} / \mathrm{L}$ & & $5.5[3.1-8.8]$ & $13.1[5.4-18.2]$ & 0.004 \\
\hline Troponin, ULN & $28 / 37$ & $15.6[5.3-84.4]$ & $10.3[0.7-37.9]$ & 0.1 \\
\hline Serum creatinine, $\mu \mathrm{mol} / \mathrm{L}$ & $30 / 34$ & 118 [89-342] & $149[93-217]$ & 0.7 \\
\hline \multicolumn{5}{|l|}{ Lowest in-ICU value } \\
\hline Platelet count, G/L & & $56[30-103]$ & 25 [9-38] & $<0.0001$ \\
\hline Prothrombin time, $\%$ & & $43[35-60]$ & 34 [16-55] & 0.03 \\
\hline \multicolumn{5}{|l|}{ Outcome } \\
\hline In-ICU-acquired infection & & $19(61.3)$ & $28(73.7)$ & 0.2 \\
\hline Fungal infection & & $3(9.7)$ & $9(23.7)$ & 0.1 \\
\hline Transplantation & & $7(22.6)$ & $1(2.6)$ & 0.01 \\
\hline Heart & & $2(6.5)$ & $1(2.6)$ & $\mathrm{n} / \mathrm{a}$ \\
\hline Heart-kidney combined & & $1(3.2)$ & $0(0)$ & $\mathrm{n} / \mathrm{a}$ \\
\hline Lung & & $4(12.9)$ & $0(0)$ & $\mathrm{n} / \mathrm{a}$ \\
\hline Left ventricular assist device & & $1(3.2)$ & $1(2.6)$ & 0.9 \\
\hline
\end{tabular}


Table 4 (continued)

\begin{tabular}{|c|c|c|c|c|}
\hline Characteristic & $n / n^{*}$ & $\begin{array}{l}\text { Survivors } \\
n=31\end{array}$ & $\begin{array}{l}\text { Nonsurvivors } \\
n=38\end{array}$ & Pvalue \\
\hline Weaning & & $23(74.2)$ & $6(15.8)$ & $<0.0001$ \\
\hline In-ICU mortality & & $0(0)$ & 37 (97.4) & $<0.0001$ \\
\hline
\end{tabular}

Continuous variables are expressed as mean \pm standard deviation or median [interquartile range] and were compared with Student's $t$-test or Wilcoxon's rank test; categorical variables are expressed as $n(\%)$ and were compared with $\chi^{2}$ tests

ICU intensive care unit, LVEF left ventricle ejection fraction, RESP Respiratory Extracorporeal Membrane Oxygenation Survival Prediction, SAPS Simplified Acute Physiology Score, SAVE Survival after Veno-Arterial ECMO, SOFA Sequential Organ-Failure Assessment, SRD systemic rheumatic disease, ULN upper limit of normal value, VA-NV-ECMO venoarterial/venovenous extracorporeal membrane oxygenation, VTI velocity-time integral

* Numbers of survivor/nonsurvivor data available

Table 5 Univariable and multivariable analyses of factors associated with in-hospital mortality of the 69 ECMO-treated SRD flare patients

\begin{tabular}{|c|c|c|c|c|c|c|}
\hline \multirow[t]{2}{*}{ Factor } & \multicolumn{3}{|c|}{ Univariable analysis } & \multicolumn{3}{|c|}{ Multivariable analysis } \\
\hline & HR & $95 \% \mathrm{Cl}$ & $P$ value & HR & $95 \% \mathrm{Cl}$ & $P$ value \\
\hline Age $\geq 40$ years & 1.5 & $0.7-2.8$ & 0.2 & & & \\
\hline Women & 1.7 & $0.8-3.4$ & 0.1 & & & \\
\hline Pre-admission SRD lung involvement & 0.6 & $0.3-1.1$ & 0.08 & 0.7 & $0.4-1.5$ & 0.4 \\
\hline Pre-admission SRD heart involvement & 1.8 & $0.9-3.5$ & 0.07 & 2.9 & $1.4-6.0$ & 0.003 \\
\hline In-ICU SRD diagnosis & 1.1 & $0.6-2.0$ & 0.8 & & & \\
\hline Pre-admission corticosteroids & 1.7 & $0.9-3.1$ & 0.1 & & & \\
\hline Pre-admission immunosuppressant(s) & 1.5 & $0.8-2.9$ & 0.2 & & & \\
\hline Day-0 SAPS $\| \geq 70$ & 2.4 & $1.2-4.7$ & 0.01 & 3.1 & $1.5-6.5$ & 0.002 \\
\hline Day-0 SOFA $\geq 16$ & 2.9 & $1.5-5.6$ & 0.001 & & & \\
\hline Symptom-onset-to-ICU interval $\geq 10$ days & 1.6 & $0.8-3.1$ & 0.2 & & & \\
\hline VA-ECMO & 1.2 & $0.6-2.2$ & 0.6 & & & \\
\hline In-ICU corticosteroids & 0.7 & $0.4-1.6$ & 0.5 & & & \\
\hline In-ICU immunosuppressant(s) & 0.9 & $0.5-1.7$ & 0.8 & & & \\
\hline Vasopressors & 5.9 & $0.8-43.0$ & 0.08 & 2.8 & $0.3-21.7$ & 0.3 \\
\hline Mechanical ventilation & 1.9 & $0.3-14.2$ & 0.5 & & & \\
\hline Renal replacement therapy & 2.1 & $1.1-4.0$ & 0.03 & 0.5 & $0.2-1.4$ & 0.2 \\
\hline ICU-acquired infection & 1.0 & $0.5-2.2$ & 0.9 & & & \\
\hline \multicolumn{7}{|l|}{ Highest In-ICU value } \\
\hline Arterial lactate $\geq 7.5 \mathrm{mmol} / \mathrm{L}$ & 2.7 & $1.4-5.2$ & 0.004 & 2.7 & $1.3-5.3$ & 0.006 \\
\hline Bilirubin $\geq 125 \mu \mathrm{mol} / \mathrm{L}$ & 2.2 & $1.1-4.5$ & 0.02 & 2.4 & $1.1-4.9$ & 0.02 \\
\hline \multicolumn{7}{|l|}{ Lowest in-ICU value } \\
\hline Platelet count <50 G/L & 3.2 & $1.3-7.7$ & 0.009 & 1.5 & $0.6-4.6$ & 0.4 \\
\hline
\end{tabular}

Bold values indicates statistically significant in multivariable analysis

The multiple Cox proportional hazards model used backward-stepwise variable elimination (with the variable exit threshold set at $P>0.10$ ). All potential explanatory variables included in the multivariable analyses were subjected to colinearity analysis with a correlation matrix. Variables associated with one another were not included in the model. Statistical significance was defined as $P<0.05$

ICU intensive care unit, SAPS Simplified Acute Physiology Score, SOFA Sequential Organ Failure Assessment, SRD systemic rheumatic diseases, VA-ECMO venoarterialextracorporeal membrane oxygenation

Nine $(10 \%)$ patients with refractory heart $(n=5)$ or lung $(n=4)$ failure could be successfully bridged to emergency transplantation. While urgent cardiac transplantation in patients under VA-ECMO is frequent, lung transplantation of unlisted patients on VV-ECMO is unusual. We advocate that SRD patients, especially young patients, who could not be weaned-off ECMO, should be considered for heart or lung transplantation.

SRD diagnosis, corticosteroid and immunosuppressant use before ICU admission or thereafter were not 
associated with in-hospital mortality for the entire population. However, specific SRD heart involvement known before ICU admission was associated with poorer outcomes, independently of VA-ECMO cannulation. That finding underlines the impact of heart sequalae from previous SRD flares on these patients' prognoses. Conversely, patients receiving VA-ECMO support for the first SRD manifestation had poorer outcomes, underscoring the severity of SRD myocardial involvement.

Importantly, for the VV-ECMO-treated subgroup, a vasculitis diagnosis was strongly and independently associated with favorable outcomes. Their intra-alveolar hemorrhages were usually quickly reversible under specific regimens combining corticosteroids, rituximab/cyclophosphamide and plasma exchanges. Our results strongly support the use of VV-ECMO for these patients.

Corticosteroid and immunosuppressant administration can be associated with in-ICU-acquired infection, especially for patients on ECMO. Indeed, our series' infection frequency was high, but rates were similar for infection vs. flare admissions, despite the latter having more frequently received corticosteroids and immunosuppressant(s). The rates of ventilator-associated pneumonia and bloodstream infections were in accordance with those in the ESLO database for VVECMO-treated patients [22]. Invasive fungal infections were particularly high $(15 \%)$ and ventilator-associated pneumonia was independently associated with in-hospital mortality of VV-ECMO-treated patients, suggesting that careful attention should be paid to infectious complications in these profoundly immunosuppressed patients.

Our study has limitations and strengths. First, despite its retrospective, observational design, many patients had rare diseases requiring a still evolving and relatively rarely used rescue technique. Second, patient inclusion lasted $>14$ years, meaning inevitable heterogeneity of diagnoses and management, but most patients were included during the last decade. Third, it is likely that ECMO support was declined for some SRD patients that were considered unfit to endure such an aggressive technique. The mortality rates herein reported should, therefore, be extrapolated with caution as they refer to an highly selected population of patients. Lastly, the main analysis considered VA- and VV-ECMO patients jointly. The reasons for ICU admission and ECMO cannulation, and the characteristics, management and outcomes of these patients obviously differ. We acknowledge that such an analysis might confound the results and their interpretation. However, the analysis aimed to present a comprehensive, real-life picture of ECMO treatment of SRD patients, with separate analyses of VA- and VV-ECMO subgroups thereafter.

\section{Conclusion}

ECMO is a relevant rescue technique for critically ill SRD patients, with $49 \%$ survival to hospital discharge. Vasculitis was independently associated with a favorable outcome of VV-ECMO-cannulated patients. Further studies are needed to specify the role of ECMO for SRD patients.

\section{Supplementary Information}

The online version contains supplementary material available at https://doi. org/10.1186/s13613-021-00819-3.

Additional file1: Table S1. Supplementary characteristics of 90 SRD Patients Given ECMO Support. Table S2. Microbiological Findings for InICU-Acquired Infections of the 90 ECMO-Treated SRD Patients. Table S3. In-ICU Characteristics and Outcomes of the 48 VA-ECMO-Treated SRD Patients: Hospital Survivors vs. Nonsurvivors. Table S4. Univariable and Multivariable Analyses of Factors Associated with In-Hospital Mortality for the 48 VA-ECMO-Treated SRD Patients. Table S5. In-ICU Characteristics and Outcomes of the 42 W-ECMO-Treated SRD Patients: Hospital Survivors vs. Nonsurvivors. Table S6. Univariable and Multivariable Analyses of Factors Associated with In-Hospital Mortality for the $42 \mathrm{VV}$-ECMO-Treated SRD Patients (DOCX $58 \mathrm{~KB}$ )

\section{Abbreviations}

ARDS: Acute respiratory distress syndrome; Cl: Confidence interval; HR: Hazard ratio; ICU: Intensive care unit; IQR: 25-75Th percentile interquartile range; LVAD: Left ventricle assist device; RESP: Respiratory Extracorporeal Membrane Oxygenation Survival Prediction; SAPS: Simplified Acute Physiology Score; SAVE: Survival after Veno-Arterial ECMO; SOFA: Sequential Organ-Failure Assessment; SRD: Systemic Rheumatic Diseases; VA-ECMO: Venoarterialextracorporeal membrane oxygenation; VV-ECMO: Venovenous extracorporeal membrane oxygenation.

\section{Acknowledgements}

None.

\section{Authors' contributions}

PB and MPdC contributed to study design, data collection, statistical analysis conduction and interpretation, manuscript writing and final approval. CEL and AC contributed to study design, statistical analysis interpretation, manuscript writing and final approval. All other authors collected data. MPdC is the study guarantor.

\section{Funding}

None.

\section{Availability of data and materials}

All data generated or analyzed during the study are included in this published article and the its supplementary information files.

\section{Ethics approval and consent to participate}

The database is registered with the "Commission Nationale de l'Informatique et des Libertés" (2217847v0). In accordance with the ethical standards of our hospital's institutional review board, the Committee for the Protection of Human Subjects, and French law, written informed consent was not needed for demographic, physiological and hospital-outcome data analyses, because this observational study did not modify existing diagnostic or therapeutic strategies; however, patients were informed of their inclusion in the study.

Consent to publication

Not applicable. 


\section{Competing interests}

The authors declare that they have no competing interests.

\section{Author details}

1 Service de Médecine Intensive-Réanimation, Hôpital La Pitié-Salpêtrière, Sorbonne Université, Assistance Publique-Hôpitaux de Paris (APHP), Paris, France. ${ }^{2}$ Service de Chirurgie Cardiothoracique, Hôpital La Pitié-Salpêtrière, Institut de Cardiologie, Sorbonne Université, APHP, Paris, France. ${ }^{3}$ Service de Médecine Interne 2, Institut E3M, Sorbonne Université, Hôpital La PitiéSalpêtrière, 47-83, Boulevard de L'Hôpital, 75651 Paris Cedex 13, France. ${ }^{4}$ Centre de Référence National Lupus Systémique, Syndrome Des Anticorps Anti-Phospholipides Et Autres Maladies Auto-Immunes Systémiques Rares, Paris, France. ${ }^{5}$ Institut de Cardiométabolisme Et Nutrition (ICAN), Sorbonne Université, INSERM, UMRS_1166-ICAN, Paris, France.

Received: 18 September 2020 Accepted: 29 January 2021 Published online: 09 February 2021

\section{References}

1. Godeau B, Boudjadja A, Dhainaut JF, et al. Outcome of patients with systemic rheumatic disease admitted to medical intensive care units. Ann Rheum Dis. 1992:51:627-31. https://doi.org/10.1136/ard.51.5.627.

2. Dumas G, Géri G, Montlahuc C, et al. Outcomes in critically ill patients with systemic rheumatic disease: a multicenter study. Chest. 2015;148:927-35. https://doi.org/10.1378/chest.14-3098.

3. Larcher R, Pineton de Chambrun M, Garnier F, et al. One-year outcome of critically ill patients with systemic rheumatic disease: a multicenter cohort study. Chest. 2020. https://doi.org/10.1016/j.chest.2020.03.050.

4. Faguer S, Ciroldi M, Mariotte E, et al. Prognostic contributions of the underlying inflammatory disease and acute organ dysfunction in critically ill patients with systemic rheumatic diseases. Eur J Intern Med. 2013;24:e40-44. https://doi.org/10.1016/j.ejim.2012.11.018.

5. Combes A, Brodie D, Bartlett R, et al. Position paper for the organization of extracorporeal membrane oxygenation programs for acute respiratory failure in adult patients. Am J Respir Crit Care Med. 2014;190:488-96. https://doi.org/10.1164/rccm.201404-0630CP.

6. Abrams D, Garan AR, Abdelbary A, et al. Position paper for the organization of ECMO programs for cardiac failure in adults. Intensive Care Med. 2018;44:717-29. https://doi.org/10.1007/s00134-018-5064-5.

7. Combes A, Hajage D, Capellier G, et al. Extracorporeal membrane oxygenation for severe acute respiratory distress syndrome. N Engl J Med. 2018;378:1965-75. https://doi.org/10.1056/NEJMoa1800385.

8. Combes A, Leprince P, Luyt C-E, et al. Outcomes and long-term quality-oflife of patients supported by extracorporeal membrane oxygenation for refractory cardiogenic shock. Crit Care Med. 2008;36:1404-11. https://doi. org/10.1097/CCM.0b013e31816f7cf7.

9. Aissaoui N, Luyt C-E, Leprince P, et al. Predictors of successful extracorporeal membrane oxygenation (ECMO) weaning after assistance for refractory cardiogenic shock. Intensive Care Med. 2011;37:1738-45. https ://doi.org/10.1007/s00134-011-2358-2.

10. Beurtheret S, Mordant P, Paoletti X, et al. Emergency circulatory support in refractory cardiogenic shock patients in remote institutions: a pilot study (the cardiac-RESCUE program). Eur Heart J. 2013;34:112-20. https:// doi.org/10.1093/eurheartj/ehs081.

11. Schmidt $M$, Burrell $A$, Roberts $L$, et al. Predicting survival after ECMO for refractory cardiogenic shock: the survival after veno-arterial-ECMO (SAVE)-score. Eur Heart J. 2015;36:2246-56. https://doi.org/10.1093/eurhe artj/ehv194.

12. Schmidt M, Bailey M, Sheldrake J, et al. Predicting survival after extracorporeal membrane oxygenation for severe acute respiratory failure. The Respiratory Extracorporeal Membrane Oxygenation Survival Prediction (RESP) score. Am J Respir Crit Care Med. 2014;189:1374-82. https://doi. org/10.1164/rccm.201311-20230C.

13. Combes A, Bréchot N, Luyt C-E, Schmidt M. What is the niche for extracorporeal membrane oxygenation in severe acute respiratory distress syndrome? Curr Opin Crit Care. 2012;18:527-32. https://doi.org/10.1097/ MCC.0b013e328357f090.

14. Pineton de Chambrun M, Bréchot N, Combes A. Venoarterial extracorporeal membrane oxygenation in cardiogenic shock: indications, mode of operation, and current evidence. Curr Opin Crit Care. 2019;25:397-402. https://doi.org/10.1097/MCC.0000000000000627.

15. Demiselle J, Auchabie J, Beloncle F, et al. Patients with ANCA-associated vasculitis admitted to the intensive care unit with acute vasculitis manifestations: a retrospective and comparative multicentric study. Ann Intensive Care. 2017;7:39. https://doi.org/10.1186/s13613-017-0262-9.

16. Kimmoun A, Baux E, Das V, et al. Outcomes of patients admitted to intensive care units for acute manifestation of small-vessel vasculitis: a multicenter, retrospective study. Crit Care. 2016;20:27. https://doi.org/10.1186/ s13054-016-1189-5.

17. Godeau B, Mortier E, Roy PM, et al. Short and longterm outcomes for patients with systemic rheumatic diseases admitted to intensive care units: a prognostic study of 181 patients. J Rheumatol. 1997;24:1317-23.

18. Moreels M, Mélot C, Leeman M. Prognosis of patients with systemic rheumatic diseases admitted to the intensive care unit. Intensive Care Med. 2005;31:591-3. https://doi.org/10.1007/s00134-005-2563-y.

19. Beil M, Sviri S, de la Guardia V, et al. Prognosis of patients with rheumatic diseases admitted to intensive care. Anaesth Intensive Care. 2017:45:6772. https://doi.org/10.1177/0310057X1704500110.

20. Heijnen T, Wilmer A, Blockmans D, Henckaerts L. Outcome of patients with systemic diseases admitted to the medical intensive care unit of a tertiary referral hospital: a single-centre retrospective study. Scand J Rheumatol. 2016;45:146-50. https://doi.org/10.3109/03009 742.2015.1067329.

21. Brünnler T, Susewind $M$, Hoffmann $U$, et al. Outcomes and prognostic factors in patients with rheumatologic diseases admitted to the ICU. Intern Med. 2015;54:1981-7. https://doi.org/10.2169/internalmedicine.54.4283.

22. Abrams D, Grasselli G, Schmidt M, et al. ECLS-associated infections in adults: what we know and what we don't yet know. Intensive Care Med. 2020;46:182-91. https://doi.org/10.1007/s00134-019-05847-z.

\section{Publisher's Note}

Springer Nature remains neutral with regard to jurisdictional claims in published maps and institutional affiliations.

\section{Submit your manuscript to a SpringerOpen ${ }^{\circ}$ journal and benefit from:}

- Convenient online submission

- Rigorous peer review

- Open access: articles freely available online

- High visibility within the field

- Retaining the copyright to your article

Submit your next manuscript at springeropen.com 